\title{
Focusing on SELF (Safety, Empowerment, Living Life Differently, and Forging a New You): Evaluating a New Approach toward Sexual Trauma Treatment for Military Service Members
}

\author{
Cristóbal S. Berry-Cabán
}

Department of Clinical Investigation, Womack Army Medical Center, Fort Bragg, NC, USA

Sabrina S. Lewis

Army-Social Work Internship Program, Womack Army Medical Center, Fort Bragg, NC, USA

Lindsey N. Thielmann

Army-Social Work Internship Program, Womack Army Medical Center, Fort Bragg, NC,

USA

Aletia L. Wilkins

Army-Social Work Internship Program, Womack Army Medical Center, Fort Bragg, NC, USA

\section{Qwanquita T. Wright}

Army-Social Work Internship Program, Womack Army Medical Center, Fort Bragg, NC, USA

Ashley Adams

Department of Clinical Investigation, Womack Army Medical Center, Fort Bragg, NC, USA 
Christopher J. Guenthner

Specialty Behavioral Health, Army-Social Work Internship Program, Womack Army Medical Center, Fort Bragg, NC, USA

\author{
Cristóbal S. Berry-Cabán, PhD (Corresponding author) \\ Womack Army Medical Center, Fort Bragg, NC, 28301 USA \\ E-mail: cristobal.s.berry-caban.civ@mail.mil
}

Received: November 15, 2019 Accepted: January 23, 2020 Published: January 25, 2020

doi:10.5296/ijsw.v7i1.15834 URL: https://doi.org/10.5296/ijsw.v7i1.15834

\begin{abstract}
Sexual assault is a pervasive problem in the United States military. The U.S. Department of Defense established the Sexual Assault Prevention and Response Office as the centralized helm of all sexual assault efforts. Their focus however, is on prevention, surveillance, and the reporting of sexual assault. Safety, Empowerment, Living Life Differently and Forging a New You (SELF) was designed at a large military treatment facility as a supplemental treatment option for female active-duty service members who require additional clinical services in an outpatient setting. SELF's goal is to facilitate change and instill hope in trauma survivors by providing psychoeducation and utilizing evidenced-based interventions that focus on the developmental, psychological, and social impact of trauma. A total of 19 female active-duty soldiers completed all eight sessions. Pre- and post-test data were available for 23 participants. Numerical variables were reported in medians and interquartile ranges. All categorical variables were reported in counts and frequencies. Paired pre- and post- Post-Traumatic Stress Disorder Checklist (PCL-5) differences were analyzed using the Wilcoxon Signed Rank and differences in initial PCL-5 score between attendance adherence groups were determined using the Kruskal Wallis test. Results show a mean decrease of 10 from baseline $(p=.001)$. SELF may provide a supplement to current treatment modalities for survivors of sexual trauma.
\end{abstract}

Keywords: Sexual trauma, Soldiers, Women, Alternative treatment modality, Post-traumatic stress disorder

\title{
1. Introduction
}

Sexual assault, a prevalent problem in our society, can impact a survivor's mental, physical and emotional health. Sexual assault is common: one in three women experience sexual violence involving physical contact during their lifetime. The CDC reports an estimated $43.9 \%$ of women experienced some form of sexual assault during their lifetime, including forced penetration, sexual coercion, unwanted sexual contact, and non-contact unwanted 
sexual experiences (Breiding et al., 2014). Nearly one in five women have experienced completed or attempted rape during her lifetime (Centers for Disease Control and Prevention, 2019).

Sexual assault in the United States military is a significant public health concern that negatively impacts military readiness (Masciotra, 2016; U.S. Department of Defense, 2014, 2016a, 2018, 2019). Survivors of sexual assault experience a variety of symptoms that can impair their ability to function. Wide ranging consequences include lost work hours, lost time in training, and hours of command involvement, thus hindering the military's ability to defend the nation (Allard, Nunnink, Gregory, Klest, \& Platt, 2011; Bean-Mayberry et al., 2011; Tiet, Leyva, Blau, Turchik, \& Rosen, 2015; Walsh et al., 2014).

Sexual assault occurs when physical, sexual activity is engaged in without the consent of the other person, or when the other person is unable to consent to the activity. The activity or conduct may include physical force, violence, threat, intimidation, ignoring the objections of the other person, causing the other person's intoxication or incapacitation (through the use of drugs or alcohol) or taking advantage of the other person's intoxication (including voluntary intoxication). Sexual harassment includes behavior such as unwelcome sexual advances, requests for sexual favors, and other conduct of a sexual nature. This is conduct that affects a person's employment or education or interferes with a person's work or educational performance or creates an environment that a reasonable person would find intimidating, hostile, or offensive (University of California, 2018).

In the Department of Defense, the term sexual assault does not refer to one specific crime. DOD policy defines sexual assault as follows: Intentional sexual contact characterized by use of force, threats, intimidation, or abuse of authority or when the victim does not or cannot consent. The term includes a broad category of sexual offenses consisting of specific offenses, including: rape, sexual assault, aggravated sexual contact, abusive sexual contact, forcible sodomy (forced oral or anal sex), or attempts to commit these acts (U.S. Department of Defense, 2014, 2017a, 2017b). For the sake of this article, the DOD's definition of sexual assault is used.

The prevalence rate of sexual assault during military service ranges from $9 \%$ to $43 \%$ among women compared to the estimated prevalence rate among the U.S. general population of $28-33 \%$ of females (Castro, Kintzle, Schuyler, Lucas, \& Warner, 2015; Stander \& Thomsen, 2016). These data are concerning, as the number of reported incidents of sexual assault far underrepresent the number of assaults that actually occur (Morral, Gore, \& Schell, 2015).

A longitudinal study on the association of sexual trauma with health and occupational outcomes, showed victims of sexual trauma are more likely to report difficulties at work, as well as, poorer mental and physical health when compared to individuals who did not experience sexual trauma (Millegan et al., 2015). Thirty percent of rape survivors experienced an episode of major depression compared to $10 \%$ of non-victims of crime (Zinzow, Britt, McFadden, Burnette, \& Gillispie, 2012). Survivors of sexual assault are more likely than non-survivors to abuse substances, including alcohol, to control the symptoms experienced after being sexually assaulted (Najavits et al., 2007). They are six times more likely to use cocaine and ten times more likely to use other major drugs (Najavits et al., 2007). Sexual trauma in the military is correlated with higher rates of post-traumatic stress disorder 
(PTSD), with PTSD occurring in $50 \%$ of women with sexual trauma compared to $15 \%$ of women without any military background (Pandey, Ashfaq, Dauterive III, MacCarthy, \& Copeland, 2017).

Past incidents of sexual trauma have correlated with increased rates of re-victimization (Castro et al., 2015). More than 33\% of women who report sexual assault prior to the age of 18 experience sexual assault as an adult (Black et al., 2011; Classen, Palesh, \& Aggarwal, 2005). Subsequent studies, in an attempt to identify effective interventions for sexual assault victims, identified depressive symptoms, maladaptive coping strategies and lack of assertiveness, as a link between victimizations (Culatta, Clay-Warner, Boyle, \& Oshri, 2017; Filipas \& Ullman, 2006).

Military environments foster unique pressures that facilitate sexual assault despite core values emphasizing mutual respect and protection (U.S. Department of Veterans Affairs, 2016). Prior to January 2016, female service members were excluded from full participation in military service, including combat roles which often led to promotion to higher-ranking positions (Allard et al., 2011; Holland, Rabelo, \& Cortina, 2014; Stander \& Thomsen, 2016; Turchik \& Wilson, 2010). The dearth of female service members in high ranking positions creates a power differential between males and females in the military that can contribute to the reinforcement of gender based stereotypes (Castro et al., 2015; Holland et al., 2014; Sadler, Booth, Cook, \& Doebbeling, 2003; Turchik \& Wilson, 2010). Although there is little research available on the impact of historical discrimination against women in the military (Tilghman, 2015), negative attitudes towards women are a salient risk factor for gender-based trauma (Nayak, Byrne, Martin, \& Abraham, 2003; Thomas \& Taylor, 2015). Female service members who report sexual assault may experience social and professional retaliation, administrative/adverse action or even punishment. (Castro et al., 2015; Holland et al., 2014; Sadler et al., 2003; Turchik \& Wilson, 2010).

In 2005, the DOD established the Sexual Assault Prevention and Response Office (SAPRO) as the centralized helm of all sexual assault efforts (U.S. Department of Defense, 2016b). However, the SAPRO's focus is on prevention, surveillance, and reporting of sexual assault. All branches, with the exception of the Coast Guard are overseen by SAPRO and implement their own sexual assault prevention programs in accordance with DOD guidelines (US Department of Defense, 2017). In 2019, SAPRO reported an overall increase from prior years in the amount of unwanted sexual contact and sexual harassment to those enrolled in military service academies (U.S. Department of Defense, 2019). Over the last decade, this number has continued to trend upward for both active duty and DOD personnel (U.S. Department of Defense \& Inspector General, 2019).

\section{Program Description}

There are multiple treatment modalities that have been used for survivors of sexual trauma such as eye movement desensitization and reprocessing (EMDR) (Davidson \& Parker, 2001; Russell, Silver, Rogers, \& Darnell, 2007; Shapiro, 2017), cognitive-behavioral therapy (CBT) (Bryan et al., 2016; Butler, Chapman, Forman, \& Beck, 2006; Hollon \& Beck, 2013; Monson et al., 2006), and cognitive processing therapy (CPT) as an adjunct to individual therapy. Cognitive therapy interventions and exposure therapy were found to be most effective in treating military veterans with PTSD (Filipas \& Ullman, 2006; Resick et al., 2017). Several 
randomized controlled trials illustrate the efficacy of cognitive therapy interventions for individuals with PTSD (Monson et al., 2006; Morland, Hynes, Mackintosh, Resick, \& Chard, 2011; Morland et al., 2015; Resick et al., 2017). A meta-analysis and a study concluded the use of cognitive group therapy as a sole treatment to be inferior to individual therapy alone among military populations (Filipas \& Ullman, 2006; Resick et al., 2017).

Focusing on SELF (Safety, Empowerment, Living Life Differently, and Forging a New You) hereafter referred to as SELF, incorporates a combination of CBT and CPT as treatment modalities. This eclectic protocol consists of service members meeting once weekly, for ninety minute sessions, over the course of eight weeks.

The Department of Behavioral Health (DOBH) at Fort Bragg, $\mathrm{NC}$ is a growing organization that offers comprehensive services to the military community using evidenced based modalities. The DOBH is responsible for providing care to over 45,000 Fort Bragg service members. Full provider schedules may lead to poorer outcomes as service members in need of increased care are occasionally unable to schedule timely follow up appointments.

SELF was designed as a quality improvement project to increase access to care by offering weekly group treatment to female active duty service members who have experienced sexual assault. SELF serves as a supplemental treatment option for female service members who require additional clinical services in an outpatient setting. SELF's goal is to aid in the facilitation of change and instill hope in trauma survivors by providing psychoeducation and therapy utilizing aspects of CBT and CPT, mindfulness, and progressive muscle relaxation with a focus on the developmental, psychological, and social impact of trauma.

SELF is held every Thursday from 1:30 to 3:00 pm. DOBH providers refer female active duty service members to this group while continuing to engage the service member in individual treatment. Upon completion of the eight-week trauma survivors group, the clinical team communicates with the service member's provider regarding the service member's progress. The service member's provider makes the final determination regarding follow-up appointments and other treatment options. In the event of an emergency, the DOBHs walk-in provider examines the service member to determine further treatment needs. The service member's assigned provider is notified of any emergency situation telephonically within 24 hours.

This study included five cohorts of the on-going SELF group. In the first session, service members complete a psychological assessment known as the Post-Traumatic Stress Disorder (PTSD) Checklist (PCL-5), engage in introductions, discuss group rules, and learn goal setting using SMART goals (Table 1). SMART goals are goals that are specific, measurable, achievable, relevant, and time-bound (Conzemius \& O'Neill, 2006). The second session focuses on emotional reconstruction, boundaries, acceptance, identifying triggers, coping mechanisms and self-care. The third session focuses on healthy communication, developing trust and self-love, and discussing manipulation power and control. In the fourth session, members learn anchoring techniques, share their stories, and practice mindfulness. In the fifth session members continue to share their stories with a focus on trauma and its effects on their platonic and romantic relationships, and intimacy. The sixth session focuses on post traumatic growth with a discussion of risk factors, cognitive distortions, and rape myths while exploring feelings of blame, shame, and guilt. In the seventh session, members write a letter 


\section{Macrothink}

International Journal of Social Work

ISSN 2332-7278

2020, Vol. 7, No. 1

to their abuser and explore their feelings of anger. In the final session, members discuss forgiveness, provide feedback to the providers, identify lessons learned, engage in an ending activity, and complete the final PCL-5. Each session is supplemented with homework in the form of SMART goals that are created by the service members in session, as well as journaling exercises. This group was designed to primarily treat women due to the higher rates of sexual trauma in this population (Breiding et al., 2014).

Mental health providers are tasked with treating the symptoms of sexual assault in order to assist the survivors' improved functioning in their personal and professional lives. This study examines the efficacy of the treatment group SELF.

\section{Methods}

This study is a prospective pre-test post-test design. All participants were female soldiers exposed to traumatic events who experienced clinically significant psychological or behavioral symptoms. This study was reviewed by the Human Protections Administrator at Womack Army Medical Center and received approval as a quality improvement project and deemed not human subject research.

Table 1. Session overview

\begin{tabular}{ll}
\hline Week & Topic \\
\hline 1 & Orientation \\
& Introductions \\
& Expectations \\
& Goal-setting \\
\hline 2 & Exploring Your Trauma \\
& Emotional Reconstruction \\
& Boundaries, Acceptance, Self-Care \\
& Triggers, Moods, Coping Mechanisms \\
& Healing from Trauma through Empowerment \\
& Healthy Communication \\
& Trust, Self-Love \\
& Manipulation, Power, and Control \\
& Stories \\
& Anchoring \\
& Practicing Mindfulness \\
\hline 5 & Stories: Trauma and its Effects \\
& Partners, Family, Friends, Work \\
& Intimacy \\
& Anniversaries \\
\hline
\end{tabular}


6

Post-Traumatic Growth

Risk Factors, Victims, Vulnerability

Blame, Shame, Guilt

Rape Myths

\begin{tabular}{ll}
\hline 7 & The Path Ahead \\
& Letter to Abuser(s) \\
& Anger \\
\hline 8 & The Path Ahead \\
& Forgiveness \\
& Feedback, Lessons \\
& Ending \\
\hline
\end{tabular}

\subsection{Data Collection}

The efficacy of this group was measured using the PCL-5. The PCL-5 is a psychological assessment tool commonly used to assess the presence of PTSD in individuals (DeMatteo et al., 2014; Hare, Black, \& Walsh, 2003; U.S. Department of Veterans Affairs \& National Center for PTSD, 2017). The PCL-5 is a psychometrically sound instrument. The PCL-5 is a 20 -item inventory that assesses the 20 symptoms of PTSD found in the Diagnostic and Statistical Manual of Mental Disorders 5 (DSM-5)(American Psychiatric Association, 2013). The PCL-5 is a self-report measure that can be completed in approximately ten minutes. The PCL-5 was found to have a good internal consistency of .96, a test-retest reliability of .84 and convergent and discriminant validity (Bovin et al., 2016).

Evidence for the PCL-5 for DSM-5 suggests that a 5 to 10 point change represents reliable change (i.e., change not due to chance) and a 10 to 20 point change represents clinically significant change (U.S. Department of Veterans Affairs \& National Center for PTSD, 2017).

\subsection{Data Analysis}

Numerical variables were reported in medians and interquartile ranges. All categorical variables were reported in counts and frequencies. Paired pre- and post-PCL-5 differences were analyzed using the Wilcoxon Signed Rank, and differences in initial PCL-5 score were determined using the Kruskal Wallis test. Analysis was conducted using SAS 9.4 (SAS Institute, Cary NC). Inferential analyses were considered significant if the corresponding $p$ value was less than 0.05 and all applicable tests were two-tailed.

\section{Results}

Forty participants overall were enrolled in five separate cohorts, each consisting of no more than 12 subjects. Of the 40,19 active-duty participants attended all eight sessions (47.5\%), 12 missed consecutive final sessions, or "dropped out" (30.0\%), six missed non-consecutive sessions or had "sporadic attendance" (15.0\%) and three participants (7.5\%) never attended a session (Figure 1). 


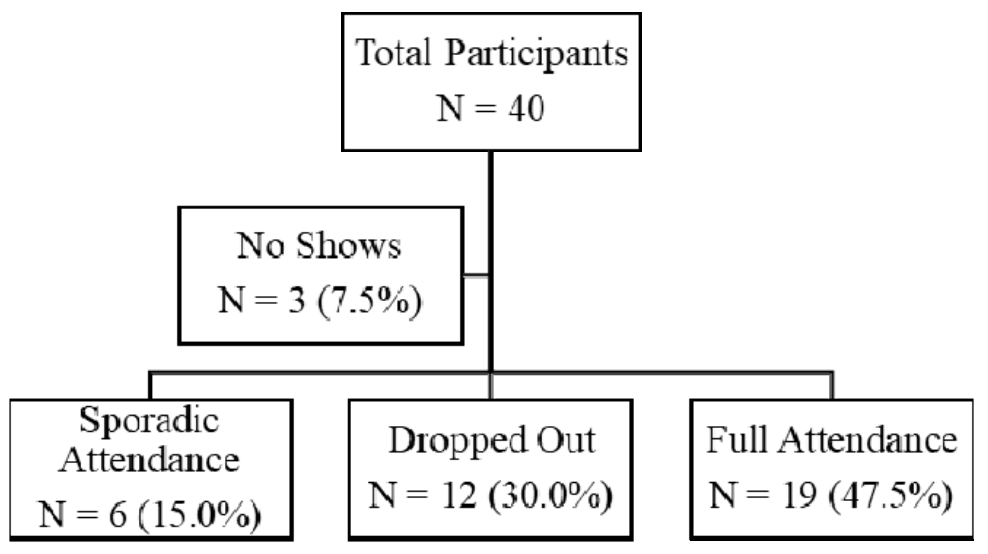

Figure 1. SELF enrollee participation

The median participant age was 25 years (IQR: 21-31 years, Table 2). Most participants were active-duty Soldiers (42.5\%) or in the midst of a Medical Evaluation Board process (soldiers that do not meet medical retention standards) (37.5\%) and the majority held an enlisted rank (92.5\%). Participants were evenly split between single, never married (37.5\%) and married $(37.5 \%)$, though a small number were divorced $(10.0 \%)$.

Pre- and post-SELF session data were available for 23 participants $(57.5 \%)$; this includes the 19 who attended all eight sessions, and four who attended sporadically. For these patients, the

Table 2. SELF enrollee participant characteristics

\begin{tabular}{ll}
\hline Characteristic & N (\%) \\
\hline Age [Q1-Q3] & $25.0[21.0-31.0]$
\end{tabular}

Duty Status

Active Duty

Medical Evaluation Board

Separating, Separated, or Retired

Not Reported

\section{Most Recent Rank}

E1-E3 (Private, Private First Class)

E4 (Specialist, Corporal)

E5 or higher (Staff or Master Sergeant, Sergeant Major)

$12(30.0)$

Officers

Not Reported

\section{Marital Status}

Single, Never Married

Married 
Divorced

Not Reported

$6(15.0)$

median PCL-5 score decreased significantly from pre- to post- SELF sessions (53.0 to 43.0, $p$ $=0.0016$; Figure 2). There were no significant differences in the pre-SELF session PCL-5 scores between participants who attended sporadically, dropped out, or completed all eight sessions $(p=0.8756)$.

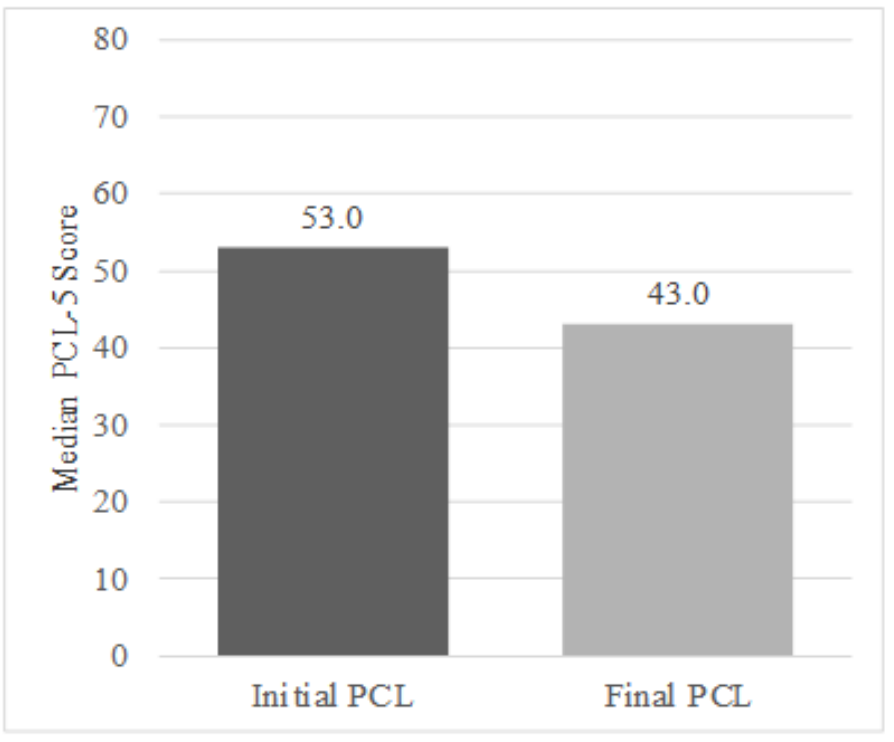

Figure 2. Pre- and Post-SELF Session PCL-5 Scores

\section{Discussion}

The purpose of this study was to examine the efficacy of the SELF intervention in treating military sexual trauma in female service members. Data showed that there was an average 10 point decrease in PCL-5 scores. This indicates that SELF was effective in contributing to the reduction of PTSD reducing symptoms among female service members.

Service members with military sexual trauma may fear reprisal from reporting the assault and the impact reporting may have on their social and professional lives. The male dominant, hyper masculine social structure of the military is one which reinforces gender norms. Problem resolution is handled within the lowest possible levels amongst the team. This can cause harassment to go unreported. Junior service members become more vulnerable to sexual assault or harassment when their harasser outranks them. These factors foster a cultural environment that facilitates sexual assault (Castro et al., 2015; Holland, Rabelo, \& Cortina, 2014). Of those who attended SELF, $50 \%$ of the female service members were junior enlisted. This number could indicate increased vulnerability to sexual assualt in this population or it could be attributed to a greater willingness to report sexual assault as a result of the larger societal shift in discussion with regard to sexual assualt.

Avoidance of hypervigilance and triggers are two PTSD symptoms that may limit the sexual assault survivors' ability to seek individual treatment. SELF provides an all-female group, 
including female providers, to address feelings of avoidance and hypervigilance in female service members with PTSD. This supplemental form of treatment allows reluctant service members to access care with other group members, thus increasing their willingness to seek in depth treatment.

\subsection{Limitations}

This study included a small group size of 40 total participants with a large attrition rate. $47.5 \%$ of the cohort attended all sessions. The rate of attrition can be attributed to $7.5 \%$ of service members who never attended the group, $7.5 \%$ of service members were separating, separated or retired from the Army, $37.5 \%$ of the service members were in the medical evaluation board process that involves increased medical appointments and results in an early separation from the military. The eighth session had a higher attrition rate that may be a result of participants experiencing difficulty with termination of group. The sporadic attendance of the service members can be attributed to a demanding training schedule that did not allow for them to attend all sessions, deployments, and the medical evaluation board process.

This was a quality improvement project to improve access to care for female service members who experienced military sexual assault. As such, the study did not control for the type of sexual assault or its severity.

\section{Conclusion}

Sexual assault in the military has a negative impact on military readiness. SELF was created as a supplement to individual treatment with the goal of improving access to care for female service members who experienced a military sexual trauma. The PCL-5 scores showed a 10 point decrease in symptoms of PTSD in service members. A 5 to 10 point change represents reliable change (i.e., change not due to chance) and a 10 to 20 point change represents clinically significant change. This suggests SELF was effective as a supplement to individualized standard of care treatments.

This group will continue to treat female service members. Moving forward, changes will be made to address the attrition rate. Group facilitators will contact service members' commanders to gain command approval for a limited work schedule during the course of treatment. The PCL-5 will be given to the group members every session. The group size will increase from twelve members to fifteen to accommodate natural attrition. Qualitative data will be collected to determine the factors contributing to the attrition rate and to gather feedback from group participants. Individuals will be assessed and oriented to the group a week before the cohort starts. Future studies can be conducted to determine how these changes have improved the quality of the group.

\section{Disclaimer}

The views expressed herein are those of the authors, and do not reflect the official policy of the Department of the Army, Department of Defense, or the United States Government. This study used no outside funding of any kind.

\section{References}


Allard, C. B., Nunnink, S., Gregory, A. M., Klest, B., \& Platt, M. (2011). Military sexual trauma research: A proposed agenda. Journal of Trauma \& Dissociation, 12(3), 324-345. https://doi.org/10.1080/15299732.2011.542609

American Psychiatric Association. (2013). Diagnostic and statistical manual of mental disorders (DSM-5) (5 ed.): American Psychiatric Publishing. https://doi.org/10.1176/ appi.books.9780890425596

Bean-Mayberry, B., Yano, E. M., Washington, D. L., Goldzweig, C., Batuman, F., Huang, C., ... Shekelle, P. G. (2011). Systematic review of women veterans' health: Update on successes and gaps. Women's Health Issues, 21(4, Supplement), S84-S97.

Black, M., Basile, K., Breiding, M., Smith, S., Walters, M., Merrick, M., ... Stevens, M. (2011). National Intimate Partner and Sexual Violence Survey: 2010 summary report. Atlanta, GA: Centers for Disease Control and Prevention.

Bovin, M. J., Marx, B. P., Weathers, F. W., Gallagher, M. W., Rodriguez, P., Schnurr, P. P., \& Keane, T. M. (2016). Psychometric properties of the PTSD checklist for diagnostic and statistical manual of mental disorders-fifth edition (PCL-5) in veterans. Psychological Assessment, 28(11), 1379-1391. https://doi.org/10.1037/pas0000254

Breiding, M. J., Smith, S. G., Basile, K. C., Walters, M. L., Chen, J., \& Merrick, M. T. (2014). Prevalence and characteristics of sexual violence, stalking, and intimate partner violence victimization - National Intimate Partner and Sexual Violence Survey, United States, 2011. Morbidity and Mortality Weekly Report, 63(8), 1-18.

Bryan, C. J., Clemans, T. A., Hernandez, A. M., Mintz, J., Peterson, A. L., Yarvis, J. S., ... Consortium, S. S. (2016). Evaluating potential iatrogenic suicide risk in trauma-focused group cognitive behavioral therapy for the treatment of PTSD in active duty military personnel. Depression and Anxiety, 33(6), 549-557. https://doi.org/10.1002/da.22456

Butler, A. C., Chapman, J. E., Forman, E. M., \& Beck, A. T. (2006). The empirical status of cognitive-behavioral therapy: A review of meta-analyses. Clinical Psychology Review, 26(1), 17-31. https://doi.org/10.1016/j.cpr.2005.07.003

Castro, C. A., Kintzle, S., Schuyler, A. C., Lucas, C. L., \& Warner, C. H. (2015). Sexual assault in the military. Current Psychiatry Reports, 17(54), 1-13. doi:10.1007/s11920-015-0596-7

Centers for Disease Control and Prevention. (2019, March 12). Preventing sexual violence. Retrieved from https://www.cdc.gov/violenceprevention/sexualviolence/fastfact.html

Classen, C. C., Palesh, O. G., \& Aggarwal, R. (2005). Sexual revictimization: A review of the empirical literature. Trauma, Violence, \& Abuse, 6(2), 103-129. https://doi.org/10.1177/1524838005275087

Conzemius, A., \& O'Neill, J. (2006). The power of SMART goals: Using goals to improve student learning. Bloomington, IN: Solution Tree.

Culatta, E., Clay-Warner, J., Boyle, K. M., \& Oshri, A. (2017). Sexual revictimization: A routine activity theory explanation. Journal of Interpersonal Violence, https://doi.org/10.1177/0886260517704962. 
Davidson, P. R., \& Parker, K. C. H. (2001). Eye movement desensitization and reprocessing (EMDR): A meta-analysis. Journal of Consulting and Clinical Psychology, 69(2), 305-316. https://doi.org/10.1037/0022-006X.69.2.305

DeMatteo, D., Edens, J. F., Galloway, M., Cox, J., Smith, S. T., \& Formon, D. (2014). The role and reliability of the Psychopathy Checklist-Revised in US sexually violent predator evaluations: A case law survey. Law and human behavior, 38(3), 248-255. doi:http://dx.doi.org/10.1037/lhb0000059

Filipas, H. H., \& Ullman, S. E. (2006). Child sexual abuse, coping responses, self-blame, posttraumatic stress disorder, and adult sexual revictimization. Journal of Interpersonal Violence, 21(5), 652-672. https://doi.org/10.1177/0886260506286879

Hare, R. D., Black, P. J., \& Walsh, Z. (2003). The psychopathy checklist-revised: Forensic applications and limitations. In R. P. Archer \& E. M. A. Wheeler (Eds.), Forensic Uses of Clinical Assessment Instruments (2 ed., pp. 230-265). Toronto, ON: Routledge.

Holland, K. J., Rabelo, V. C., \& Cortina, L. M. (2014). Sexual assault training in the military: Evaluating efforts to end the "invisible war". American Journal of Community Psychology, 54(3), 289-303. https://doi.org/10.1007/s10464-014-9672-0

Hollon, S. D., \& Beck, A. T. (2013). Cognitive and cognitive-behavioral therapies. In M. J. Lambert (Ed.), Bergin and Garfield's Handbook of Psychotherapy and Behavior Change (6 ed., pp. 393-442). Oxford: John Wiley.

Masciotra, D. (2016). Military violence and scandal: We need a public discussion of the sexual assault epidemic in our armed forces. July. Retrieved from http://www.salon.com/2016/07/16/military_violence_and_scandal_we_need_a_public_discus sion_of_the_sexual_assault_epidemic_in_our_armed_forces/

Millegan, J., Milburn, E. K., LeardMann, C. A., Street, A. E., Williams, D., Trone, D. W., \& Crum-Cianflone, N. F. (2015). Recent sexual trauma and adverse health and occupational outcomes among US service women. Journal of Traumatic Stress, 28(4), 298-306. https://doi.org/10.1002/jts.22028

Monson, C. M., Schnurr, P. P., Resick, P. A., Friedman, M. J., Young-Xu, Y., \& Stevens, S. P. (2006). Cognitive processing therapy for veterans with military-related posttraumatic stress disorder. Journal of Consulting and clinical Psychology, 74(5), 898-907. https://doi.org/10. 1037/0022-006X.74.5.898

Morland, L. A., Hynes, A. K., Mackintosh, M. A., Resick, P. A., \& Chard, K. M. (2011). Group cognitive processing therapy delivered to veterans via telehealth: A pilot cohort. Journal of Traumatic Stress, 24(4), 465-469.

Morland, L. A., Mackintosh, M. A., Rosen, C. S., Willis, E., Resick, P., Chard, K., \& Frueh, B. C. (2015). Telemedicine versus in-person delivery of cognitive processing therapy for women with posttraumatic stress disorder: A randomized noninferiority trial. Depression and Anxiety, 32(11), 811-820. https://doi.org/10.1002/da.22397

Morral, A. R., Gore, K. L., \& Schell, T. L. (2015). Sexual assault and sexual harassment in the US Military Volume 2: Estimates For Department of Defense service members from the 2014 RAND military workplace study. https://doi.org/10.7249/RR870.2-1 
Najavits, L. M., Harned, M. S., Gallop, R. J., Butler, S. F., Barber, J. P., Thase, M. E., \& Crits-Christoph, P. (2007). Six-month treatment outcomes of cocaine-dependent patients with and without PTSD in a multisite national trial. Journal of Studies on Alcohol and Drugs, 68(3), 353-361. https://doi.org/10.15288/jsad.2007.68.353

Nayak, M. B., Byrne, C. A., Martin, M. K., \& Abraham, A. G. (2003). Attitudes toward violence against women: A cross-nation study. Sex Roles, 49(7-8), 333-342. https://doi.org/10.1023/A:1025108103617

Pandey, N., Ashfaq, S. N., Dauterive III, E. W., MacCarthy, A. A., \& Copeland, L. A. (2017). Military sexual trauma and obesity among women veterans. Journal of Women's Health. https://doi.org/10.1089/jwh.2016.6105

Resick, P. A., Wachen, J. S., Dondanville, K. A., Pruiksma, K. E., Yarvis, J. S., Peterson, A. L., ... Hembree, E. A. (2017). Effect of group vs individual cognitive processing therapy in active-duty military seeking treatment for posttraumatic stress disorder: A randomized clinical trial. JAMA Psychiatry, 74(1), 28-36. https://doi.org/10.1001/jamapsychiatry. 2016.2729

Russell, M. C., Silver, S. M., Rogers, S., \& Darnell, J. N. (2007). Responding to an identified need: A joint department of defense/department of veterans affairs training program in eye movement desensitization and reprocessing (EMDR) for clinicians providing trauma services. International Journal of Stress Management, 14(1), 61-71.

Sadler, A. G., Booth, B. M., Cook, B. L., \& Doebbeling, B. N. (2003). Factors associated with women's risk of rape in the military environment. American Journal of Industrial Medicine, 43(3), 262-273. https://doi.org/10.1002/ajim.10202

Shapiro, F. (2017). Eye movement desensitization and reprocessing (EMDR) therapy, third edition: Basic principles, protocols, and procedures (3 ed.). New York, NY: Guilford Press.

Stander, V. A., \& Thomsen, C. J. (2016). Sexual harassment and assault in the U.S. Military: A review of policy and research trends. Military Medicine, 181(1 Suppl), 20-27. https://doi.org/10.7205/MILMED-D-15-00336

Thomas, K. H., \& Taylor, S. P. (2015). Bulletproofing the psyche: Mindfulness interventions in the training environment to improve resilience in the military and veteran communities. Advances in social work, 16(2), 312-322. https://doi.org/10.18060/18357

Tiet, Q. Q., Leyva, Y. E., Blau, K., Turchik, J. A., \& Rosen, C. S. (2015). Military sexual assault, gender, and PTSD treatment outcomes of U.S. veterans. Journal of Traumatic Stress, 28(2), 92-101. https://doi.org/10.1002/jts.21992

Tilghman, A. (2015, December 3). All combat jobs open to women in the military. MilitaryTimes.

Turchik, J. A., \& Wilson, S. M. (2010). Sexual assault in the U.S. military: a review of the literature and recommendations for the future. Aggression \& Violent Behavior, 15(4), 267-277. https://doi.org/10.1016/j.avb.2010.01.005

U.S. Department of Defense. (2014, November). Report to the President of the United States on sexual assault prevention and response. Retrieved from http://sapr.mil/public/ docs/reports/fy14_potus/fy14_dod_report_to_potus_full_report.pdf 
U.S. Department of Defense. (2016a). Department of Defense annual report on sexual assault in the military: Fiscal year 2015. Retrieved from http://www.sapr.mil/public/docs/reports/ FY15_Annual/FY15_Annual_Report_on_Sexual_Assault_in_the_Military.pdf

U.S. Department of Defense. (2016b). SAPRO Sexual Assault Prevention and Response Office. Retrieved from http://sapr.mil/index.php

U.S. Department of Defense. (2017a). Department of Defense directive number 6495.01: Sexual Assault Prevention and Response (SAPR) Program. 20.

U.S. Department of Defense. (2017b). Department of Defense Instruction 6495.02: Sexual Assault Prevention and Response (SAPR) Program Procedures, March 28, 2013 [Incorporating Change 3, May 24, 2017]

U.S. Department of Defense. (2018, May 4). Department of Defense annual report on sexual assault in the military: Fiscal year 2017. Retrieved from http://sapr.mil/ public/docs/reports/FY17_Annual/DoD_FY17_Annual_Report_on_Sexual_Assault_in_the _ Military.pdf

U.S. Department of Defense. (2019, April 9). Department of Defense annual report on sexual assault in the military: Fiscal year 2018. Retrieved from https://www.sapr. $\mathrm{mil} / \mathrm{sites} /$ default/files/DoD_Annual_Report_on_Sexual_Assault_in_the_Military.pdf

U.S. Department of Defense, \& Inspector General. (2019). Memorandum for Under Secretary of Defense for Personnel and Readiness Superintendent, United States Military Academy Commander, United States Army Criminal Investigation Command Evaluation of the DoD's Handling of Incidents of Sexual Assault Against (or Involving) Cadets at the United States Military Academy (Project Number D2019-DIPOIV-0157.000) (pp. https://media.defense.gov/2019/May/2017/2002132905/-2002132901/-2002132901/2002132 901/D2002132019-DIPOIV-2002130157.2002132000_REDACTED.PDF). Alexandria, VA.

U.S. Department of Veterans Affairs. (2016). Understanding military culture: Expression of values and ideals by service branch. Retrieved from http://www.mentalhealth. va.gov/communityproviders/docs/values.pdf

U.S. Department of Veterans Affairs, \& National Center for PTSD. (2017). PTSD Checklist for DSM-5 (PCL-5) Retrieved from https://www.ptsd.va.gov/professional/assessment/ adult-sr/ptsd-checklist.asp

University of California. (2018). University of California - Policy sexual violence and sexual harassment (pp. 25).

US Department of Defense. (2017). Department of Defense annual report on sexual assault in the military: Fiscal year 2016. Retrieved from Washington, DC:

Walsh, K., Koenen, K. C., Cohen, G. H., Ursano, R., Gifford, R. K., Fullerton, C. S., \& Galea, S. (2014). Sexual violence and mental health symptoms among National Guard and Reserve soldiers. Journal of General Internal Medicine, 29(1), 104-109. https://doi.org/10.1007/ s11606-013-2555-5

Zinzow, H. M., Britt, T. W., McFadden, A. C., Burnette, C. M., \& Gillispie, S. (2012). Connecting active duty and returning veterans to mental health treatment: Interventions and treatment adaptations that may reduce barriers to care. Clinical Psychology Review, 32(8), 741-753. https://doi.org/10.1016/j.cpr.2012.09.002 


\section{Macrothink}

International Journal of Social Work

ISSN $2332-7278$ 2020, Vol. 7, No. 1

\section{Copyright Disclaimer}

Copyright reserved by the author(s).

This article is an open-access article distributed under the terms and conditions of the Creative Commons Attribution license (http://creativecommons.org/licenses/by/3.0/). 